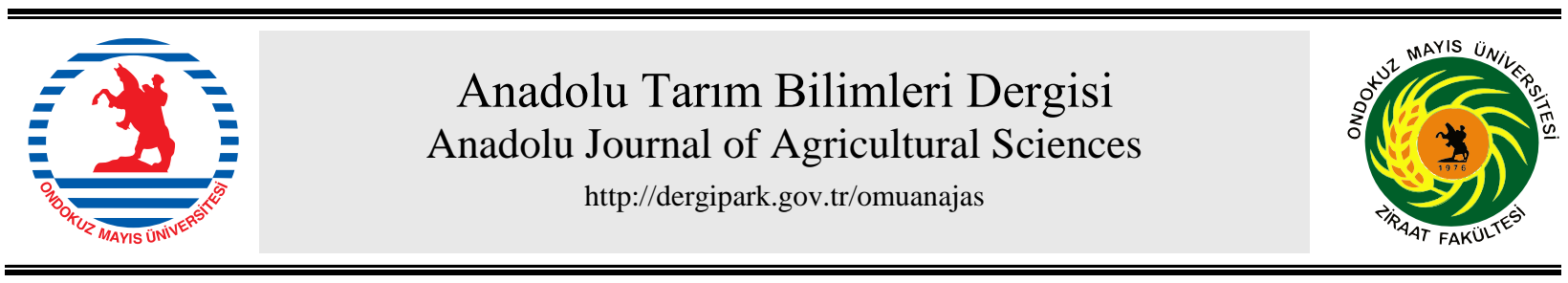

\section{Araştırma/Research}

Anadolu Tarım Bilim. Derg./Anadolu J Agr Sci, 35 (2020) ISSN: 1308-8750 (Print) 1308-8769 (Online) doi: 10.7161/omuanajas.691385

\title{
Bazı entomopatojen nematod türlerinin zeytin fidantırtılı Palpita unionalis Hübner (Lepidoptera: Pyralidae)'e karşı virülensliğinin araştırılması ${ }^{1}$
}

\author{
๑Hürkan Ataş ${ }^{\mathrm{a}}$, 『Çiğdem Gözel ${ }^{\mathrm{a}}$, ĐUğur Gözel ${ }^{\mathrm{a}^{*}}$ \\ ${ }^{a}$ Çanakkale Onsekiz Mart Üniversitesi, Ziraat Fakültesi, Bitki Koruma Bölümü, Çanakkale, Türkiye
}

*Sorumlu yazar/corresponding author: ugozel@comu.edu.tr

Geliş/Received 19/02/2020 Kabul/Accepted 17/06/2020

\begin{abstract}
ÖZET
Bu çalışmada Steinernema affine 46, S. feltiae 96, S. carpocapsae 1133 ve Heterorhabditis bacteriophora 1144 izolatlarının son dönem Palpita unionalis (Hübner) larvalarına karşı virülenslikleri laboratuvarda platelerde ve iklim odasında saksılarda araştırılmıştır. Entomopatojen nematodların etkinlikleri, 12 çukurlu platelerde iki farklı uygulama dozu kullanılarak (25 ve 50 İnfektif Juvenil (IJ)/larva) $25^{\circ} \mathrm{C}^{\prime}$ de belirlenmiştir. Saksı denemesi her bir saksıya 10 adet $P$. unionalis larvası ile tek uygulama dozu kullanılarak (40.000 IJ/saks1) $25{ }^{\circ} \mathrm{C}$ 'de yürütülmüştür. Nematod türüne ve uygulama yoğunluğuna bağlı olarak platelerdeki larvalarda meydana gelen ölüm oranı \%83.3-100 iken, saksılardaki ölüm oranı \%50-100 olarak belirlenmiştir. Hem plate hem de saksı denemelerinde kullanılan EPN türleri içerisinde $P$. unionalis larvalarında en yüksek etkinliği \%90-100 ölüm oranı ile H. bacteriophora meydana getirmiştir.
\end{abstract}

Investigation of the virulence of some entomopathogenic nematode species against olive leaf moth Palpita unionalis Hübner (Lepidoptera: Pyralidae)

\section{ABSTRACT}

In this study the virulence of Steinernema affine 46, S. feltiae 96, S. carpocapsae 1133 and Heterorhabditis bacteriophora 1144 isolates against the last instar larvae of Palpita unionalis (Hübner) were investigated on plates in laboratory and pots in a climate room. Efficacy of entomopathogenic nematodes were determined at $25{ }^{\circ} \mathrm{C}$ using two different application doses (25 and 50 Infective Juveniles (IJs)/larva) in 12 well plates. In pot experiment, $10 \mathrm{P}$. unionalis larvae were inoculated in each pot, by using a single application dose (40.000 IJs/pot) at $25{ }^{\circ} \mathrm{C}$. Depending on the nematode species and application dose, the larvae mortality occurred in plates was $83.3-100 \%$, while the mortality in pots was $50-100 \%$. Among the EPN species used in both plate and pot experiments, $H$. bacteriophora resulted in the highest efficacy on $P$. unionalis larvae with $90-100 \%$ mortality.

Anahtar Sözcükler: Palpita unionalis Entomopatojen nematod Zeytin Biyolojik mücadele
Keywords:

Palpita unionalis

Entomopathogenic nematode

Olive

Biological control 


\section{Giriş}

Zeytin (Olea europea L.), anavatanı olan Anadolu'da ve Akdeniz iklimi görülen ülkelerde yetiştiriciliği yapılan bir bitkidir. Dünyada başta Akdeniz'e kıyısı olan ülkeler olmak üzere toplam 41 ülkede zeytin yetiştiriciliği yapılmaktadır. Yaklaşık 10 milyon hektar alanda yetiștirilen zeytinin bașlıca üreticileri İspanya, Yunanistan, İtalya ve Türkiye'dir (FAO, 2017). Türkiye'nin 1.500.467 ton olan üretim miktarının 426.995 tonu sofralık, 1.073 .472 tonu da yağlık olarak değerlendirilmektedir (TÜİK, 2018).

Zeytin bitkisinde önemli kayıplara neden olan birçok zararlı bulunmaktadır. Kovancı ve Kumral (2004), Bursa İlindeki zeytinliklerde zeytin güvesi Prays oleae (Bernard) (Lep.: Praydidae) ve zeytin sineği Bactrocera oleae (Gmelin) (Diptera: Tephritidae)'nin ana zararlı olduğunu ve Palpita unionalis'e karşı yapılan geniş spektrumlu insektisitlerin zararlının doğal düşmanlarını yok ettiğinden, potansiyel olarak önemli bir zararlı olabileceğini vurgulamışlardır. El-Kifl ve ark., (1974), P. unionalis'in Kuzey Misır'da zeytinin ana zararlıs1 olduğunu belirtmişlerdir. Ayrıca İran'daki zeytin bahçelerinde zeytin fidantırtılının bir karantina zararlısı olarak ilk defa 1999 yılında kayda geçtiği bildirilmiştir (Khaghaninia ve Pourabad, 2009).

Altı larva dönemi geçiren $P$. unionalis, ilk larva döneminden itibaren zeytin bitkisinin taze sürgünlerinde ve tomurcuklarında oburca beslenmektedir. Özellikle genç zeytin fidanlarında beslenen zararlı, taze sürgün ve yapraklara giderek yaprağın parankima dokusunda beslenip yaprağ 1 dantelimsi bir hale getirirler. İleri larva dönemlerinde ve yoğun bulaşıklık durumunda zararın arttığı hatta meyve etinde dahi beslendiği bildirilmiştir (Kaçar, 2011). Zararlı multivoltin bir tür olup, İsrail'de 6 döl (Avidov ve Rosen, 1961), Fransa'da yılda 2 döl (Balachowsky ve ark., 1972), Mısır'da 10 döl (El-Kifl ve ark., 1974), İtalya'da 4-5 döl (Fodale ve Mule, 1990) ve Türkiye'de ise 2 tam 1 yarım döl verdiği kaydedilmiştir (Kovancı ve ark., 2006). Bir dişinin ömrü boyunca ortalama yaklaşık 600 yumurta bıraktığı (Avidov ve Rosen, 1961) ve zararlının tüm gelişme dönemlerinde ağaçta aktif olarak bulunduğundan dolayı kimyasal mücadelesinin zor olduğu bilinmektedir (Hegazi ve ark., 2005).

Zeytin fidantırtılının mücadelesinde en çok tercih edilen yöntem kimyasal mücadeledir. Ancak zararlının çok döl vermesi, fazla sayıda yumurta bırakması, kullanılan sentetik pestisitlerin doğaya ve doğal düşmanlar üzerindeki olumsuz etkileri gibi nedenlerden dolayı, zararlı ile mücadelede alternatif yöntemlerden biyolojik mücadele uygulamalarının önemi artmaktadır.

Günümüzde biyolojik mücadele içerisinde günden güne önemi artan entomopatojen nematodlar (EPN), ticari preparat olarak üretilmekte ve tarım alanlarında zararlı olan pek çok zararlı türe karşı başarılı bir şekilde uygulanmaktadırlar (Grewal ve ark., 2005). Obligat böcek paraziti olan EPN'ler, vücutlarında taşıdıkları mutualistik bakteriler ile konukçularını 24-48 saat içerisinde öldürebilmektedirler (Grewal and Georgis, 1999).

Doğal yaşam alanı olan toprakta konukçusu olmadığ durumlarda, EPN'ler aylarca canlılıklarını koruyabilmektedir. İnfektif juveniller (IJs), infekte ettikleri ve besin olarak kullandıkları böcek tükendiğinde kütikulayı parçalar ve yeni konukçular aramak için kadavradan dışarı çıkarlar (Grewal and Georgis, 1999).

$\mathrm{Bu}$ çalışmada ülkemiz topraklarından elde edilmiş olan 4 farklı yerel EPN türünün P. unionalis larvaları üzerindeki etkinliği laboratuvarda ve iklim odasında denenmiştir. Ülkemizde bu zararlının biyolojik mücadelesinde EPN'lerin kullanımı ile ilgili herhangi bir çalışma bulunmamaktadır. Bu nedenle elde edilen sonuçlar ileride yapılacak çalışmalara 1 şık tutması yönünden oldukça önemlidir.

\section{Materyal ve Yöntem}

\subsection{Galleria mellonella (L.)'nın Kitle Üretimi}

EPN'leri topraktan elde etmekte kullanılan en yaygın yöntem, EPN'ye hassas bir etmeni toprakta bekleterek, zararlının nematod tarafindan infekte olmasını sağlamaktır. Özellikle büyük balmumu güvesi Galleria mellonella L. (Lepidoptera: Pyralidae)'nın son dönem larvaları, topraktan EPN elde etmede kullanılan en uygun konukçulardır (Bedding ve Akhurst, 1975; Mracek, 1980). EPN'ler ile ilgili yapılan çalışmalarda larva duyarlılığı, uygulama kolaylığ açısından bu konukçu tercih edilmektedir (Mracek ve ark., 1999; Griffin ve ark., 2000; Nguyen ve ark., 2004; Güneş ve Gözel, 2011). Çalışmada G. mellonella larvaları $45 \mathrm{~g}$ balmumu, $90 \mathrm{~g}$ granül maya, $307 \mathrm{~g}$ misır unu, $225 \mathrm{~g}$ bal karışımından oluşan yapay besin ortamında $27 \pm 1{ }^{\circ} \mathrm{C}$ 'de cam kavanozlarda yetiştirilmiştir (Kaya ve Stock, 1997). Yeterli sayıya ulaşan G. mellonella larvalarının bir kısmı kültürün sürekliliği için bırakılmış, diğer kısmı ise etkinlik denemelerindeki izolatların yenilenmesi için kullanılmıştır.

\subsection{Entomopatojen nematodların kitle üretimi}

Çalışmada kullanılan EPN'ler ülkemizin farklı illerinden elde edilmiş ve G. mellonella'nın son dönem larvaları üzerinde yenilenmiştir. Çalışmada yaklaşık 2-3 günlük olan IJs kullanılmıştır (Çizelge 1).

\subsection{Palpita unionalis larvalarının elde edilmesi}

Zeytin fidantırtılı larvaları Çanakkale ilinin Ayvacık ilçesine bağlı Gülpınar köyündeki zeytin fidanlarından toplanmıştır. Zeytin fidanlarının yaprak ve sürgünleri incelenerek, bulaşık örnekler toplanıp laboratuvara getirilmiştir. 
Laboratuvara getirilen $P$. unionalis larvalarının son dönemleri ayrılmış ve etkinlik denemelerinde kullanılmak üzere hazırlanmıştır.

2.4. Laboratuvarda entomopatojen nematodların Palpita unionalis larvaları üzerindeki etkinlik denemeleri

Etkinlik denemeleri 12 kuyucuklu plakalarda (plate) yürütülmüştür. Platelerin tabanına Whatmann kâğıdı yerleştirilerek her kuyucuğa bir adet son dönem $P$. unionalis larvası konulmuştur. Daha sonra her bir kuyucuktaki larvalara 2-3 günlük olan IJ'ler 25 ve 50 IJs/larva yoğunluğunda $10 \mathrm{ml}$ saf su ile uygulanmıştır.

İçerisinde $P$. unionalis son dönem larvaları olan kontrol platelerine ise sadece $10 \mathrm{ml}$ saf su uygulamas1 yapılıp, EPN uygulanmamışırı. EPN uygulaması yapıldıktan sonra nemin korunması için platelerin kapakları kapatılıp, $25{ }^{\circ} \mathrm{C}^{\prime} \mathrm{de}$ inkübatörde karanlık ortamda bekletilmiştir.

EPN uygulamaları sonrası $P$. unionalis larvaları 1., 3., 5. ve 7. günlerde binoküler mikroskop (Leica DM 1000) altında kontrol edilmiş̧ir. Yapılan gözlemlerde hareketsiz olan $P$. unionalis larvaları White trap ortamına aktarılmıştır. White traplara alınan $P$. unionalis larvaları 24 saatte bir kontrol edilmiştir (White, 1927).

Yapilan kontroller sonucunda $P$. unionalis larvalarından EPN çıkışı gözlemlenenler kayıt altına alınmıştır. $P$. unionalis larvalarında EPN gelişmesinin ve çıkışının gözlemlenmesi ile zararlı larvalarındaki ölümlerin EPN'ler tarafından meydana geldiği kesin olarak belirlenmiştir.

2.5. Sakslarda entomopatojen nematodlarin Palpita unionalis larvaları üzerindeki etkinlik denemeleri

Kontrollü koşullardaki iklim odasındaki $\left(25{ }^{\circ} \mathrm{C}\right.$ sıcaklık, \%65 nem) saksı denemelerinde 1.5 yaşındaki Gemlik (Tirilye) çeşidi zeytin fidanları kullanılmıştır. Her bir izolat ve kontrol uygulaması için 5 adet saksı kullanılmıştır. İklim odasındaki her bir zeytin fidanına $10 P$. unionalis larvası konulmuş ve ardından EPN uygulaması yapılmıştır. İnokulasyondan sonra larvalar beslenmeye bırakılarak gözlemlenmiştir. Kaçar (2011), zararlının yaprakları sürgün uçlarında ördükleri bir ă̆ ile bir araya getirdiğini ve burada kışladıklarını bildirmiştir. $\mathrm{Bu}$ çalışmada da EPN'ler yaprak aralarındaki $P$. unionalis larvalarına $40.000 \mathrm{IJ} / \mathrm{saks1}$ yoğunluğunda, $100 \mathrm{ml}$ saf su ile sprey edilmiştir. Kontrol uygulamalarına ise sadece aynı yoğunlukta saf su uygulanmıştır.

EPN inokulasyonu sonrası fidanlardaki $P$. unionalis larvaları 7. günün sonunda binoküler mikroskop (Leica DM 1000) altında kontrol edilmiştir. Yapılan gözlemlerde hareketsiz olan $P$. unionalis larvaları White trap ortamına aktarılmıştır. White traplara alınan $P$. unionalis larvaları 24 saatte bir kontrol edilmiştir (White, 1927).
Yapılan kontroller sonucunda $P$. unionalis larvalarından EPN çıkışı gözlemlenenler kayıt altına alınmıştır. P. unionalis larvalarında EPN gelişmesinin ve çıkışının gözlemlenmesi ile zararlı larvalarındaki ölümlerin EPN nedeni ile meydana geldiği kesin olarak belirlenmiştir.

\subsection{Istatistiksel analiz}

Çalışmada ortaya çıkan sonuçların varyans analizleri için (MANOVA) SPSS (Version 12.00) istatistik programı kullanılmış ve ortalamaların karşılaştırması Duncan'ın çoklu karşılaştırma testine göre $P \leq 0.05$ düzeyinde yapılmıştır.

\section{Bulgular ve Tartışma}

Laboratuvarda ve iklim odası koşullarında $P$. unionalis larvalarına karşı 4 farklı yerel EPN izolatının etkinliğinin araştırıldığ çalışmada farklı ölüm oranları meydana gelmiştir. Laboratuvar koşullarında yürütülen etkinlik denemelerine ait plateler, EPN inokulasyonundan sonraki 1., 3., 5., ve 7. günlerde kontrol edilmiş, infekteli larvalar White trap ortamına aktarılmış, kadavralardaki EPN gelişimi ve çıkışı gözlemlenerek, larva ölümlerinin nematod kaynaklı olduğu doğrulandıktan sonra ölüm oranları hesaplanmıştır (Çizelge 2).

EPN inokulasyonundan sonra yapilan kontrollerde doza ve kontrol günlerine bağlı olarak zararlının larvalarındaki ölüm oranlarında artış meydana gelmiştir. 1. gün kontrolünde en fazla ölüm 50 IJs dozunda $H$. bacteriophora izolatında (\%58.3), en düşük ölüm ise ayn dozda $S$. carpocapsae ve $S$. affine izolatlarında (\%8.3) gözlemlenmiştir. Yapılan 3. gün kontrolünde ise en yüksek ölüm 50 IJs dozunda $H$. bacteriophora ve $S$. carpocapsae izolatlarında (\%75), en düşük ölüm oranı ise aynı dozda $S$. feltiae ve 25 IJs dozda $S$. affine izolatlarında (\%50) gözlemlenmiştir. 5. gün kontrolünde de en yüksek ölüm oranı 50 IJs dozda $S$. carpocapsae ve S. affine izolatlarında (\%91.6), en düşük ölüm oranı ise 25 IJs dozda S. feltiae izolatı (\%75) tarafindan gerçekleşmiştir. Son gün kontrolünde ise $P$. unionalis larvalarının neredeyse hepsinde ölüm gerçekleşmiştir. 50 IJs dozda $S$. carpocapsae, $S$. affine ve $H$. bacteriophora izolatları larvaların tamamın (\%100) öldürmüşlerdir. En düşük ölüm oranı ise $25 \mathrm{IJs}$ dozda $S$. feltiae izolatında (\%83.3) gözlemlenmiştir.

Palpita unionalis'e karşı yapılan diğer bir çalışmada; Mahmoud (2014), Mısır'da P. unionalis'e karşı S. feltiae, S. carpocapsae ve H. bacteriophora'y1 test etmiştir. Çalışma her bir nematod türü için 7 farklı doz ve 5 farklı sicaklıkta yapılmışıtır. En yüksek $\mathrm{LC}_{50}$ değerinin (22.7 IJs) H. bacteriophora tarafindan meydana geldiğini bildirmiştir. 
Kontrollü koşullardaki iklim odasında yürütülen saksı denemesi sonuçları türlere göre farklılık göstermiştir. 7. gün sonunda yapılan kontrollerde; $H$. bacteriophora ve $S$. feltiae izolatları $P$. unionalis larvalarında sırası ile \%100 ve 90 ölüme neden olmuş ve bu iki tür arasında istatistiki olarak herhangi bir farklılık bulunmamıştır. S. affine ve S. carpocapsae izolatları ise $\% 50$ ve 60 ölüm oranı istatistiki olarak diğer iki türden farklı bulunmuştur (Çizelge 3) ( $P$ : 0.000). İnfekteli larvalardaki EPN gelişimi ve çıkış1 gözlemlenerek (Şekil 1), larva ölümlerinin nematod kaynaklı olduğu doğrulandıktan sonra ölüm oranları hesaplanmıştır.

Lepidoptera takımında bulunan zararlılar, Steinernematidler ve Heterorhabditidler için oldukça duyarlı konukçular olarak kabul edilmiş, bundan dolayı hem laboratuvar hem doğa koşullarında etkinlikleri ve kullanım potansiyelleri ile ilgili birçok çalışma yürütülmüştür (Vashisth ve ark., 2013).

Siegel (2004)'de yaptıkları bir çalışmada antep fistığı ağacı üzerinde zararlı olan Amyelois transitella Walker (Lep.: Pyralidae)'ya karşı $S$. carpocapsae ve $S$. feltiae'yi uygulamışlardır. Uygulamayı pülverizatör ile $\mathrm{m}^{2}$ 'ye 50.000-1.000.000 IJ olacak şekilde yapmışlardır.
Sonuç olarak S. carpocapsae'yi S. feltiae'den daha etkili bulup, S. carpocapsae 100.000 IJ'de \%72 ölüm oranı göstermiş̧ir. Uygulamadan 21 gün sonra incelenen kadavraların \%51.3'ü nematodlar ile bulaşık bulunmuştur.

Ülkemiz topraklarından elde edilmiş S. feltiae lahana kelebeği Pieris brassicae L. (Lep.: Pieridae) larvalarında kontrollü koşullarda \%84.33 (Yurt ve ark., 2015), H. bacteriophora ise findık kurdu Curculio nucum L. (Col.: Curculionidae) larvalarında laboratuvarda kontrollü koşullarda \%90.9 (Gürel ve Gözel, 2017) gibi yüksek oranlarda ölümlere neden olmuşlardır. Ülkemizde yapılan benzer bir çalışmada da S. carpocapsae, S. feltiae ve H. bacteriophora türlerinin üç farklı yoğunluğu $(100,500$ ve $1000 \mathrm{IJ} /$ larva) ve üç farklı sicaklık $\left(10,15\right.$ ve $\left.25{ }^{\circ} \mathrm{C}\right)$ uygulamalarının $P$. operculella larvalarındaki kontrol potansiyelleri araştırılmıştır. En yüksek ölüm oranının $25^{\circ} \mathrm{C}$ 'de ve 1000 IJ yoğunluğunda $S$. carpocapsae ve $H$. bacteriophora türlerinde sirası ile $\% 96$ ve 80 olduğunu bildirmişlerdir (Kepenekçi ve ark., 2013).

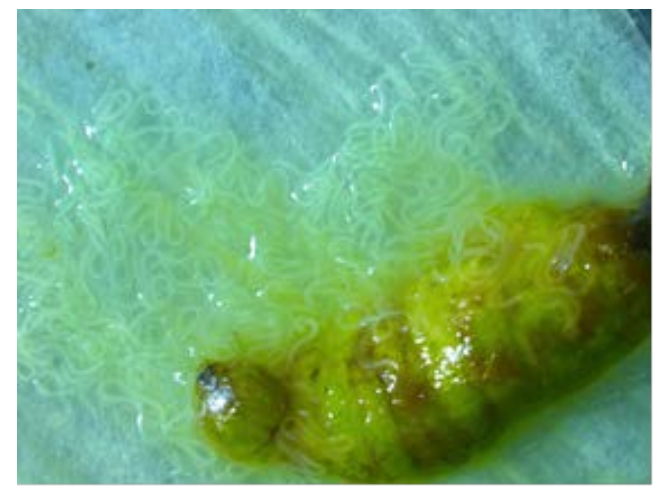

Şekil 1. İnfekteli Palpita unionalis larvasından çıkan Steinernema carpocapsae juvenilleri

Figure 1. Juveniles of Steinernema carpocapsae emerge from infected Palpita unionalis larva

Çizelge 1. Palpita unionalis larvalarına uygulanan entomopatojen nematod türleri

Table 1. Entomopathogenic nematodes species applied on the larvae of Palpita unionalis

\begin{tabular}{lll}
\hline İzolat No & \multicolumn{1}{c}{ Tür Adı } & \multicolumn{1}{c}{ Şehir } \\
46 & Steinernema affine & İstanbul \\
96 & Steinernema feltiae & Bursa \\
1133 & Steinernema carpocapsae & Sakarya \\
1144 & Heterorhabditis bacteriophora & Sakarya \\
\hline
\end{tabular}


Çizelge 2. Gün, doz ve türe göre platelerde Palpita unionalis larvalarında meydana gelen ölüm oranları (\%)

Table 2. Mortality occurred on Palpita unionalis larvae according to day, dose and species in plates (\%)

\begin{tabular}{|c|c|c|c|c|c|c|c|c|}
\hline Doz & \multicolumn{4}{|c|}{25 IJs*** } & \multicolumn{4}{|c|}{50 IJs } \\
\hline Tür* & 1. gün** & 3. gün & 5. gün & 7. gün & 1. gün & 3. gün & 5. gün & 7. gün \\
\hline \multirow{2}{*}{ S. carpocapsae } & $33.3 \pm 1.49$ & $58.3 \pm 1.38$ & $83.3 \pm 1.21$ & $91.6 \pm 1.18$ & $8.3 \pm 1.58$ & $75 \pm 1.26$ & $91.6 \pm 1.18$ & $100 \pm 1.13$ \\
\hline & D ab II & C ab II & B ab II & A ab II & $\mathrm{D}$ ab I & $\mathrm{C}$ ab I & B ab I & A ab I \\
\hline \multirow{2}{*}{ S. feltiae } & $41.6 \pm 1.45$ & $66.6 \pm 1.33$ & $75 \pm 1.26$ & $83.3 \pm 1.21$ & $25 \pm 1.52$ & $50 \pm 1.41$ & $83.3 \pm 1.21$ & $91.6 \pm 1.18$ \\
\hline & D b II & C b II & B b II & A b II & D b I & $\mathrm{Cb} \mathrm{I}$ & B b I & A b I \\
\hline \multirow{2}{*}{ S. affine } & $16.6 \pm 1.55$ & $50 \pm 1.41$ & $83.3 \pm 1.21$ & $91.6 \pm 1.18$ & $8.3 \pm 1.58$ & $58.3 \pm 1.38$ & $91.6 \pm 1.18$ & $100 \pm 1.13$ \\
\hline & D b II & C b II & B b II & A b II & $\mathrm{Db} \mathrm{I}$ & $\mathrm{Cb} \mathrm{I}$ & B b I & A b I \\
\hline \multirow{2}{*}{ H. bacteriophora } & $25 \pm 1.52$ & $66.6 \pm 1.33$ & $83.3 \pm 1.21$ & $91.6 \pm 1.18$ & $58.3 \pm 1.38$ & $75 \pm 1.26$ & $83.3 \pm 1.21$ & $100 \pm 1.13$ \\
\hline & D a II & C a II & B a II & A a II & D a I & $\mathrm{C}$ a I & B a I & A a I \\
\hline \multirow{2}{*}{ Kontrol } & $0 \pm 0.00$ & $0 \pm 0.00$ & $0 \pm 0.00$ & $0 \pm 0.00$ & $0 \pm 0.00$ & $0 \pm 0.00$ & $0 \pm 0.00$ & $0 \pm 0.00$ \\
\hline & E c III & E c III & E c III & E c III & E c III & E c III & E c III & E c III \\
\hline
\end{tabular}

*Aynı günde farklı EPN türlerinde farklı küçük harfler ile gösterilen ortalamalar arasındaki farklar istatistiksel olarak önemlidir (P: 0,000).

**Aynı EPN türünde farklı günlerde farklı büyük harfler ile gösterilen ortalamalar arasındaki farklar istatistiksel olarak önemlidir (P: 0,000).

***Aynı günde ve aynı EPN türünde farklı dozlardaki farklı roma rakamları ile gösterilen ortalamalar arasındaki farklar istatistiksel olarak önemlidir ( $P$ : 0,028).

Çizelge 3. Saksı denemesinde Palpita unionalis larvalarında meydana gelen ölüm oranları (\%)

Table 3. Mortality occurred on Palpita unionalis larvae in pot experiment (\%)

\begin{tabular}{cccccc}
\hline Tür & S. carpocapsae & S. feltiae & S. affine & H. bacteriophora & Kontrol \\
\hline Ölüm Oranı & $60 \pm 1.55 \mathrm{~b}$ & $90 \pm 0.00 \mathrm{a}$ & $50 \pm 1.55 \mathrm{~b}$ & $100 \pm 0.00 \mathrm{a}$ & $0 \pm 0.00$ \\
& & & & & \\
\hline
\end{tabular}

\section{Sonuç}

Bu çalışmada hem plate hem de saksı denemelerinde en yüksek etkinliği gösteren izolatın $H$. bacteriophora olduğu belirlenmiştir. Plate denemelerinde görülen ölüm oranları genel olarak saksı denemelerinden daha yüksek olmuştur. Bunun nedeni nematod ile konukçunun bulunduğu ortamın alan olarak farklılığından kaynaklanmaktadır. Plate ortamına oranla saksılarda bitkilerde yapılan EPN uygulamalarında doğal olarak nematodun konukçuyu bulup infekte etmesini zorlaştırmaktadır. $\mathrm{Bu}$ nedenle EPN uygulamalarından başarı elde etmek için, EPN yoğunluğu ve EPN'lerin uygulandıkları ortam etkinlik açısından en önemli faktörlerdendir.

$P$. unionalis larvalarına karşı EPN'lerin etkinliklerinin test edildiği bu çalışmada ümitvar sonuçlar elde edilmiştir. Zeytin bahçelerinde zararlının, EPN'ler ile mücadelesine yönelik kullanım potansiyellerinin ortaya konulması için detaylı doğa çalışmalarının yapılması gerekmektedir. Yapılacak olan doğa çalışmalarında kullanılacak olan izolatların etkili olmas1 durumunda kitle üretimleri yapılarak $P$. unionalis ile mücadeledeki kullanım olanakları araştırılmalıdır. 


\section{Kaynaklar}

Avidov, Z., Rosen, D., 1961. Bionomics of the jasmine moth (Glyphodes unionalis Hübn.) in the coastal plain of Israel. Bulletin of Research Council of Israel 10B: 77-89.

Balachowsky, A.S., 1972. Entomologie applique a l agriculture. Traite, Tome II, Lepidopteres, Deuxiem vol, Zygaenoidea Pyraloidea Noctuoidea, Masson et C. Ed., Paris, 1131-1133.

Bedding, R.A., Akhurst, R.J., 1975. A simple technique for the detection of insect parasitic Rhabditid nematodes in soil. Nematologica, 21: 109-110.

El-Kifl, A.H., Abdel-Salam, A.L., Rahhal, A.M.M., Kifl, A.H.-El., Abdel-Salam, A.L., 1974. Biological studies on the olive leaf moth, Palpita unionalis Hb. (Lepidoptera: Pyralidae). Bulletin de ls Societe Entomologique d'Egypte, 58: 337-344.

FAO, 2017. http://www.fao.org/faostat. (Erişim Tarihi: 12.12.2019).

Fodale, A.S., Mule, R., 1990. Bioethological observations on Palpita unionalis Hübner in Sicily and trials of defence. Acta-Horticulturae, 286: 351353.

Grewal, P.S., Georgis, R., 1999. Entomopathogenic nematodes. In F.R. Hall, and J.J. Menn, Eds. Methods in Biotechnology, vol. 5: Biopesticides: Use and Delivery. Totowa, NJ: Humana Press, pp. 271-299.

Grewal, P.S., Ehlers, R.U., Shapiro-Ilan, D.I. 2005. Nematodes as biocontrol agents. CABI Publishing, USA, 506.

Griffin, C.T., Chaerani, R., Fallon, D., Reid, A.P., Downes, M.J., 2000. Occurrence and distribution of the entomopathogenic nematodes Steinernema ssp. and Heterorhabditis indica in Indonesia. Journal of Helminthology, $\quad 74(2)$ : 143-150. https://doi.org/10.1017/S0022149X00000196.

Güneş, Ç., Gözel, U., 2011. Marmara Bölgesi'ndeki entomopatojen nematod faunasının belirlenmesi. Türkiye Biyolojik Mücadele Dergisi, 2(2): 93-102. ISSN 2146-0035.

Gürel, S., Gözel, U., 2017. Düzce İli findık bahçelerindeki entomopatojen nematod faunasının belirlenmesi ve findik kurduna (Curculio nucum L.) (Col:: Curculionidae) karşı laboratuvarda etkinliklerinin araştırılması. Türkiye Biyolojik Mücadele Dergisi, 8(1): 7-20. ISSN 2146-0035-EISSN 2548-1002.

Hegazi, E., Herz, A., Hassan, S.A., Khafagi, W.E., Agamy, E., Zaitun, A., Khamis, N., 2005. Field efficiency of indigenous egg parasitoids (Hymenoptera, Trichogrammatidae) to control the olive moth (Prays oleae, Lepidoptera, Yponomeutidae) and the jasmine moth (Palpita unionalis, Lepidoptera, Pyralidae) in an olive plantation in Egypt. Biological Control, 43(2): 171187. ttps://doi.org/10.1016/j.biocontrol.2007.07.009.

Kaçar, G.Ş., 2011. Doğu Akdeniz Bölgesi zeytinlerinde zeytin fidantırtıl1 Palpita unionalis (Hübner) (Lepidoptera: Pyralidae)'in mücadelesine esas bazı biyolojik özelliklerinin belirlenmesi. Doktora Tezi. Çukurova Üniversitesi Fen Bilimleri Enstitüsü, 131s, Adana.

Kaya, H.K., Stock, S.P., 1997. Techniques in insect nematology. In: Lacey L.A. Ed. Manual of Techniques in Insect Pathology. Biological Techniques Series. San Diego, London: Academic Press, 281-324.

Kepenekçi İ., A. Tülek, M. Alkan, Hazır, S., 2013. Biological control potential of native entomopathogenic nematodes against the potato tuber moth, Phthorimaea operculella (Zeller) (Lepidoptera: Gelechiidae) in Turkey. Pakistan Journal of Zoology, 45: 1415-1422.

Khaghaninia, S., Pourabad, R.F., 2009. Investigation on biology of olive leaf worm Palpita unionalis $\mathrm{Hb}$. (Lepidoptera: Pyralidae) in constant laboratory conditions. Munis Entomology and Zoology, 4(2): 320-326.

Kovanc1, B., Kumral, N.A., 2004. Insect pests in groves of Bursa (Turkey). $5^{\text {th }}$ International Symposium on Olive Growing. 67, 27 Sep-2 Oct, İzmir.

Kovanc1, B., Kumral, N.A., Akbudak, B., 2006. Bursa ili zeytin bahçelerinde zeytin fidantırtıl1, Palpita unionalis (Hubn.) (Lepidoptera: Pyralidae)'in popülasyon dalgalanması üzerinde araştırmalar. Türkiye Entomoloji Dergisi, 30(1): 23-32. ISSN 1010-6960.

Mahmoud, M.F., 2014. Virulence of entomopathogenic nematodes against the jasmine moth, Palpita unionalis Hb. (Lepidoptera: Pyralidae). Egyptian Journal of Biological Pest Control, 24(2): 393-397.

Mracek, Z., 1980. The use of Galleria traps for obtaining nematode parasites of insects in Czechoslovakia (Lep.: Nematoda, Steinernematidae). Acta Entomology Bohemoslovaca, 77: 378-382.

Mracek, Z., Becyar, S., Kindlmann, P., 1999. Survey of entomopathogenic nematodes from the families Steinernematidae and Heterorhabditidae (Nematoda: Rhabditida) in the Czech Republic. Folia Parasitology, 46: 145-148.

Nguyen, K.B., Shapiro-Ilan, D.I., Stuart, R.J., McCoy, C.W., James, R.R., Adams, B.J., 2004. Heterorhabditis mexicana n. sp. (Rhabditida: Heterorhabditidae) from Tamaulipas, Mexico, and morphological studies of the bursa of Heterorhabditis spp. Nematology, 6: 231-244. https://doi.org/10.1163/1568541041218031.

Siegel, J., Lacey, L.A., R. Fritts, Jr., Higbee, B.S., Noble, P., 2004. Use of Steinernematid nematodes for post harvest control of navel orangeworm (Lepidoptera: Pyralidae, Amyelois transitella) in 
fallen pistachios. Biological Control, 30(2): 410-

417.

https://doi.org/10.1016/j.biocontrol.2003.12.004.

TÜİK, 2018. https://biruni.tuik.gov.tr/medas (Erişim Tarihi: 12.12.2019).

Vashisth S., Y.S. Chandel, P.K. Sharma, 2013. Entomopathogenic nematodes-A review. Agricultural Reviews, 34: 163-175.

White, G.F., 1927. A method for obtaining infective nematode larvae from cultures. Science, 66: 302303.

Yurt, Ç., Gözel, Ç., Gözel, U., 2015. Bazı entomopatojen nematod türlerinin Pieris brassicae (Linnaeus) (Lepidoptera: Pieridae) üzerindeki etkinlikleri. Türkiye Biyolojik Mücadele Dergisi, 6: 77-84. ISSN 2146-0035. 